\title{
«GÓNGORA [...] INVENTAR UNA NUEVA LENGUA» ESCRIBIÓ LEOPOLDO MARÍA PANERO: LA HUELLA DE GÓNGORA Y OTROS BARROCOS EN LA POESÍA DE LOS NOVÍSIMOS*
}

Túa BLESA

Universidad de Zaragoza

sí, como se destaca en el título de estas páginas, escribía Leopoldo María Panero en la
introducción a su antología «Última poesía no española» ${ }^{1}$, publicada en la revista Poesía en
1979, un texto en el que además de la peculiar selección de poetas que allí se presentaba ${ }^{2}$, Panero hacía un breve y muy riguroso examen de la poesía española del siglo XX, en el que no faltaban juicios radicalmente discrepantes con el canon generalmente aceptado y que, por mucho que el canon personal de cada lector ya no es que pueda diferir del canon «oficial», sino que difiere en tal o cual obra o autor - en último término el canon no es sino un compromiso inestable de múltiples cánones particulares y en el que intervienen factores estéticos, éticos, políticos, etc.—, no deja de ser, como todo en el pensamiento y obra de Panero, singular. Entre otras opiniones, escribía que

[...] sólo sobre el vacío de una cultura tan popular como puede ser la china o la japonesa, o sin ir tan lejos la francesa, se pueden producir mitos culturales como Rafael Alberti, Salinas, Altolaguirre, León Felipe y otros muchos que han tenido la suerte de ser republicanos (Panero, 2014b: 491),

\footnotetext{
* Estas páginas continúan las dedicadas a la aludida huella en los escritos de Ignacio Prat y Eduardo Hervás (Blesa, 2017), a las que seguirán otros trabajos que atiendan a esto mismo en otros de los poetas novísimos. Por otro lado, dado que en parte tienen que ver con la intertextualidad, sirven para homenajear al querido y admirado amigo José Enrique Martínez Fernández, a quien se debe, entre otros trabajos siempre interesantes, el libro La intertextualidad literaria (Martínez Fernández, 2001). Páginas, pues, para José Enrique, un amigo de los de verdad.

${ }^{1}$ Escribo en cursiva el no del título; en su publicación en la revista Poesía, tanto en el índice como en el texto, todo el título aparece en mayúsculas, destacadas las de no en un tipo menor.

${ }^{2}$ Estos son los poetas últimos, divididos como en la antología de José María Castellet Nueve novísimos poetas españoles en dos grupos. Seniors: Antonio Martínez Sarrión, Pere Gimferrer, Ana María Moix, Guillermo Carnero; La coqueluche: Félix de Azúa, Francisco Ferrer Lerín, Antonio Colinas, Eduardo Haro, Juan Luis Panero, Gabriel Bocángel, Enrique Murillo (Enrique Hegewicz) y como colofón un «Romance anónimo» titulado «Canción por la muerte de Federico García Lorca». Los cinco primeros figuraban también en la antología de Castellet; por otra parte, aunque se mantiene la división señalada, se ha alterado el lugar al que se adscribía a Ana María Moix.
} 
en lo que queda diluido cualquier mérito poético de algunos de los grandes poetas contemporáneos algún otro de los nombrados no lo es tanto--, cuyo prestigio no sería sino consecuencia de su posición política. De lo injusto, si no atrabiliario de la crítica paneresca en ese texto, bastará añadir que opinaba que «en cuanto a Aleixandre, su edición francesa lo ha descubierto como siendo nada más que lo que es, poeta menor para una antología», o esto otro: «[s]alvo en el 27 un poquito de Lorca, un poco más de Cernuda» o «y no necesito decir que [Antonio] Machado no me gusta; es como poesía para el bachillerato» (Panero, 2014b: 491) .

Es el caso que, aunque las páginas de «Última poesía no española» se centraban en la poesía contemporánea, se dan en ellas varias menciones de Góngora, y de algún otro de los poetas barrocos.

Una de ellas está en función de, siguiendo en esto un tópico discutido, poner su poesía en relación con la de Stéphane Mallarmé, un tema ya clásico en los estudios literarios, cuyo comienzo, según ha señalado Andrés Sánchez Robayna, habría tenido como pioneros a

[...] Alfonso Reyes [quien] asegura haber asociado «ligeramente» los nombres de Góngora y Mallarmé «allá en 1909 o 1910, en cierta conferencia». Pero fue Rémy de Gourmont, en 1912 (Promenades littéraires, 4 ${ }^{\mathrm{a}}$ serie), el primero en dejar constancia de ese designio de acercamiento. (Sánchez Robayna, 1983: 17)

Es el caso que Panero expone en el mencionado trabajo una diferencia teórica esencial al distinguir entre la «Literatura misma» y la «literatura sobre la vida» - donde el uso de mayúscula y minúscula es ya significativo-. La Literatura misma, escribe,

[...] es una crítica de la realidad —o debe ser-, incluso cuando precisamente por serlo se aleja de ella, criticando a la lectura, haciéndola difícil o imposible, como en Góngora y Mallarmé; pero no puede dejar de referirse a ella, y ello descifra la aridez de Góngora, no la de Mallarmé: y es que en España no ha habido nunca lectura: desde que se fueron los juglares se acabó esa costumbre. Y es por ello que la literatura castellana prácticamente no existe (Panero, 2014b: 490).

Que la conclusión es excesiva de todo punto no necesita mayores comentarios. Y no es la única ocasión en que Panero expresó juicios semejantes. Casi veinte años después, en 2007, en Papá, dame la mano que tengo miedo, texto en prosa de tonalidad autobiográfica, se lee una nueva descalificación general de la poesía con expresión fuertemente despectiva y coloquial y de varios de los autores españoles canónicos del período contemporáneo, que da pie a un elogio de Góngora y otros poetas barrocos más: «Y la poesía es caca, porque Juan Ramón no merece la pena, ni Lorca, ni Cernuda, ni Valle Inclán, ni Azorín; sólo merece la pena Góngora, la poesía del barroco, si acaso Juan de Tarsis o el Conde Villamediana, Gabriel de Bocángel.» (Panero, 2007: 104)

Y está la cuestión de la Literatura misma, la que se distancia de la vida para proyectarse sobre sí misma. En otro lugar, el prólogo a Visión de la literatura de terror anglo-americana, Panero se ha referido a esa misma idea como «literatura orgánica», que es «todo lo contrario de una literatura ingenua: no tiene, pues, ese horror puritano por las “citas"», sino que otorga «a la cita, a la lectura y a

\footnotetext{
${ }^{3}$ Para un examen más amplio de las opiniones de Leopoldo María Panero sobre la poesía española remito a (Blesa, en prensa).
} 
la traducción el máximo valor, como los más arriesgados exponentes de la naturaleza sistemática de la literatura.» (Panero, 1977: 29)

Literatura misma, pues, cuyo representante máximo sería la poesía de Mallarmé, que es una referencia proclamada una y otra vez en la escritura paneresca - las de Ezra Pound y T. S. Eliot completan la tríada de las predilecciones del poeta-y, desde luego, la que más reiteradamente se incorpora en ella, nada menos que un centenar de ocasiones, muy especialmente a partir de Poemas del manicomio de Mondragón (1987) y no estará de más dejar constancia de que los intertextos mallameanos, como sucede también con los de otros autores, son tan sólo unos pocos que se repiten y repiten de poema a poema, de libro a libro.

Un Mallarmé al que, tiempo después, en un poema de Abismo (1999) denominaría «el Rey»: «como el Rey dijo, / sólo una línea monótona / verde castillo del vacío» y, aunque el lector reconoce sin duda la intertextualidad con «Une sonore, vaine et monotone ligne», verso de L'après-midi d'un faune, un asterisco remite a una nota al pie que aclara: «El Rey es Stéphane Mallarmé» (Panero, 2011a: 49). ${ }^{4}$ Caso, el citado, de intertexto marcado, según la terminología de José Enrique Martínez (Martínez Fernández, 2001: 96-102), el que incluye la fuente de lo citado, tipo que en la poesía de Panero es el más común y que, refundiendo las diversas formas de la atribución utilizadas — (lo) dijo», «dijera», «dixit», etc., el nombre del autor sin verbo-, da lugar a lo que debería considerarse como una figura que añadir al repertorio de la retórica, figura para la que no parece mala denominación la de «X dixit», según propuse en (Blesa, 2011: 23). Cita incorporada $\mathrm{y}$ «X dixit» que no es sino una de las manifestaciones del plagio o copia o imitación como procedimiento de composición y que tiene su consigna en un conocido dictum de Lautréamont - Teoría lautreamontiana del plagio es el título de un libro de Panero de 1999_- un procedimiento que es una de las restricciones adoptadas por los miembros de Oulipo - reescribir un texto con algunas variantes, véase la colección de veintinún autorretratos presentados en C'est un métier d'homme (Oulipo, 2010)—y tantos otros y que encuentra en textos de Ignacio Prat algunos de los ejemplos de reproducción textual más sobresalientes; así, su «Las intrigas venecianas o el síndrome Myslowitz-Braunschweig» es, salvo unas pocas palabras, una extensa copia de parte de un texto de José María Blanco White y de parte de otro de Walter Benjamin (Prat, 1983: 131-137; Blesa, 1990, 2008). Por lo demás, Panero había teorizado sobre la literatura orgánica en el prólogo arriba citado, orgánica «por cuanto en ella no hay para la literatura referentes exteriores — la realidad o la vida—» y en la que su «único referente es ella misma» (Panero, 1977: 28). En una entrevista de ese mismo año, 1977, el poeta respondía al preguntarle Biel Mesquida «ipor qué hablas con tantas citas?»:

Porque son la prevención de la censura que se va a imponer a ideas muy simples, que no necesitan citas, pero que necesitan pasar por lo que ha sido escrito, por todos los datos que ya existen, que ya existían todos y que no hacía falta más que conectarlos (Mesquida, 1977: 13a).

\footnotetext{
${ }^{4}$ Las citas de la poesía de Panero las tomo de las recopilaciones Poesía completa. 1970-2000 y Poesía completa 20002010, salvo, como es obvio, que pertenezcan a los libros posteriores a esta última. El gran número de intertextos en la escritura de Panero es más que llamativo y se ha señalado en diversas ocasiones, véase sobre todo el interesante (Rodríguez de Arce, 2009).
} 
Vuelve sobre lo mismo en Prueba de vida: «tantas citas me valen para ser escuchado, y creído, no desoído sistemáticamente como hace el psicoanálisis y/o la psiquiatría»; y también allí mismo: «Y tanta cita para enmascarar un hombre que ya no es» (Panero, 2002: 45 y 55). Leopoldo María Panero dixit.

Años antes, en las entrevistas que realizó Federico Campbell a diversos escritores españoles entre 1969 y 1970, Mallarmé es una constante en las declaraciones de Panero e interesa lo que allí se lee. Tras decir que en aquellos momentos había dos únicas vías para la poesía, el surrealismo y Mallarmé, se privilegia esta segunda por ser reflexiva: a la pregunta de Campbell «¿Mallarmé es reflexivo?» responde «Es reflexión sobre el vacío»(Campbell, 1971: 17), lo que le sirve para poco después caracterizar su propia escritura a partir del poema «Ann Donne: Undone» con que se cierra Así se fundó Carnaby Street (1970), como reflexiva (Campbell, 1971: 18).

Teóricamente, pues, la poesía de Panero, sería práctica de la Literatura misma, tendría en la de Mallarmé uno de sus fundamentos y es innegable que la cuestión del vacío - reitero estos versos: «como el Rey dijo, / sólo una línea monótona / verde castillo del vacío»-, la palabra misma, recorre su obra, sin embargo es notable la diferencia en lo formal: el cuidado exquisito del poeta francés no se corresponde en absoluto con el descuido general de los poemas panerescos. La riqueza de las rimas de Mallarmé, por mencionar tan sólo eso, encuentra en los poemas rimados de Panero una pobreza extrema: por citar un par de casos, hasta cuatro veces «boca» rima consigo misma y dos a su vez «poema» en el texto titulado precisamente «La rosa de Mallarmé», un poema de diez versos, del libro de 1994 Orfebre (Panero, 2001: 489-490); de nuevo «boca» se reitera hasta en cinco ocasiones y rima con «convoca» en los ocho versos de «Decía Nietzsche» de Teoría del miedo (Panero, 2011a: 60). ¿Rimas? Sin duda, pero, lejos de las riqueza de las mallarmeanas, más bien «paupérrimas», rimas que, como señalé en otra ocasión, «habrán de verse, ya no como inexperiencia o torpeza, sino más bien en cuanto ironía —o, mejor, burla descarnada - de este componente tradicional» (Blesa, 2001: 10). En cualquier caso, como ya he señalado, es cierto que, entre las múltiples intertextualidades que se leen en sus poemas, las expresiones mallarmeanas, ya en francés, ya traducidas, ocupan cuantitativamente el primer lugar, por encima de lo que se cita de Ezra Pound o T. S. Eliot, además de que el nombre del poeta figura en numerosas ocasiones y también Béatrice o Beatriz de la famosa expresión mallarmeana «La destruction fut ma Béatrice» ${ }^{4}$.

Por otra parte, la pésima opinión que, hemos visto, le merece a Panero la cultura española regresa en muy variados textos. Así, el ensayo «Es-pa-ña» de 1978 es, según advierte el subtítulo, un «Manifiesto anti español» (Panero, 2014: 47-49), Contra España y otros poemas no de amor es el título de un libro de 1990, además «este lugar parecido al Infierno, / que llaman España» son versos de Last river together (Panero, 2001: 220), «Spain is pain / España es dolor y muerte y maldición» lo son de Escribir como escupir (Panero, 2011a: 449) o, por añadir sólo un pasaje más, «España es una mierda» se lee en Tragos (Panero, 2011a: 541), entre otros textos que se podrían citar, de ahí que en (Blesa, en prensa) proponga que se considere a Leopoldo María Panero como poeta no español. 
Volviendo al texto de «Última poesía no española». Un poco más adelante de la cita antes recogida, al criticar el modo de circulación de los discursos y siguiendo la conocida propuesta de Louis Althuser - en «su vinculación a través de esos "aparatos ideológicos" que son la enseñanza pública, la información, el espectáculo, las editoriales, los antólogos, los premios literarios» (Panero, 2014b: 491) — , se referirá para ejemplificarlo al «escándalo de que don Juan de Jáuregui haya salido sólo recientemente, gracias a Joaquín Marco, de las ediciones eruditas para pasar a una edición al menos

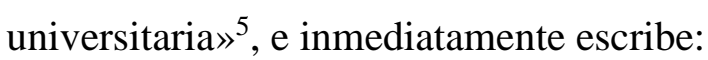

No así otros caballeros de la valía de Gabriel de Bocángel y Unzueta, de la irrealidad de cuyos escritos sólo pueden ahora nutrirse quienes se aprovechan de la falta de presencia viviente de la cultura, que es lo que origina el cáncer de la erudición; por ejemplo fantasmas como Dámaso Alonso, que se creyó en la obligación de traducir a Góngora al español, y ello quizá porque este último jamás escribió en este idioma, y lo que hizo fue quizá tratar de inventar una nueva lengua, como decía mi amigo Eduardo Hervás, joven poeta seguidor de Góngora, que se fue a descubrir lo que era la poesía abriendo una tarde el gas. (Panero 2014b: 491)

Sobra decir que el juicio sobre las exégesis prosificadas de las Soledades y el Polifemo, o de alguna de ellas si es que se refiere tan sólo a una, por parte de Dámaso Alonso es a todas luces injusto, pero aunque sobre es de justicia decirlo. Muy otra, por cierto, es la opinión de Alonso como poeta: el título de un artículo de 1990, «Contra Neruda o en defensa de Dámaso Alonso», es ya suficientemente explícito, además de que se refiere a él como «uno de mis amigos, poetas universales» y escribe que «me parece todavía actualmente uno de los poetas más dignos de la Generación del 27», lo que con algún otro argumento dará paso a afirmar que Alonso y él mismo son «cumbres del expresionismo» y «modernos por excelencia» (Panero, 2014b: 293 y 294). Y cabe añadir que a ello ha de responder que uno de los poemas de Teoría del miedo, de 2000, se titule «Plagio de Dámaso Alonso» (Panero, 2011a: 52) y que se le nombre en «Remake», poema del libro de 2004 Danza de la muerte: «la vida / es un monstruo — oh Dámaso Alonso—, soy como tú / un escarabajo» (Panero, 2011a: 242).

En cuanto al «joven poeta seguidor de Góngora» Eduardo Hervás al que Panero nombra y su gongorismo, remito a (Blesa, 2017). Y está claro que lo que ahí se dice de lo que Hervás opinaba de Góngora no es banal: ese «quizá tratar de inventar una nueva lengua» es proyecto en el que trabajó Hervás, en el que trabajó Panero y que en definitiva está en el presupuesto nuclear de la poesía novísima, bien que de modos diversos. Eso mismo explica bien el «no» de «Última poesía no española».

El artículo de Leopoldo María Panero «La poesía de Pere Gimferrer», de 1989, es una nueva muestra muy elocuente de que la poesía de Góngora ocupa un lugar en el canon paneresco. Allí, tras un juego con el apellido del poeta catalán que es todo un elogio — «Recuerdo que Ana María Moix me dijo una vez, bromeando acerca de la etimología del nombre de Pere “esto significa Gin-ferrer. Hijo

\footnotetext{
${ }^{5}$ Se refiere a Orfeo, ed. y pról. de Inmaculada Ferrer, Barcelona, Llibres de Sinera, 1970, libro de la colección Ocnos dirigida, como dice el texto, por Joaquín Marco; publicado el texto de Panero en 1979, lo de que la aludida edición de Orfeo hubiera tenido lugar «recientemente» hay que entenderlo de un modo bastante laxa. No cabe suponer que la redacción es algún tiempo anterior a la publicación de la antología, toda vez que figura en ella un poema de Enrique Hegewicz, cuyo único de poemas, Las dimensiones saciadas, se publicó ese mismo año.
} 
de herrero". Y era verdad, porque esto significaba "il miglior fabbro"» (Panero, 2014b: 258)—, confiesa que en un primer momento la poesía en catalán de Gimferrer «carecía de valor» para él, pero

Una segunda lectura me ha convencido de que, por el contrario, somos dos los gigantes de la poesía española actual, tal como en otro tiempo ocurrió con Quevedo y Góngora. No creo que haya ningún inconveniente en equiparar a Gimferrer con Góngora, y ello sin ningún menoscabo para los dos. (Panero, 2014b: 258)

Está claro: a la hora de señalar una poesía de la máxima categoría que pudiera equipararse a la de Gimferrer, esa es para Panero la de Góngora.

De ese mismo aprecio son testimonio las ocasiones en que en la escritura paneresca se entretejen intertextos gongorinos: en Contra España y otros poemas no de amor «del Ganges cisne adusto» es lema del poema y luego verso de «Añoranza de Alcides» (Panero, 2001: 390) - la cita procede de la Soledad primera, donde muy poco antes se nombra a Alcides-; «gime el lebrel en el cordón de seda» es lema en uno de los poemas del libro de 2002 Conversación (Panero, 2011a: 176) — «gima», etc. es verso del Polifemo; como en tantas ocasiones, Panero, que debía de citar casi siempre de memoria, altera lo citado 6 —; «campo de plumas / A la batalla contra el ser» rehace en «Masoquismo 2», poema de Erección del labio sobre la página (2004), el verso «a batallas de amor, campo de plumas» que cierra la Soledad primera; de ahí mismo ha de provenir «pavo real, campo de pluma / — lo dijo Góngora—», fragmento de ese mismo libro (Panero, 2011a: 207); «te amaré desnudo contra el ser — campo de plumas / como Góngora dijera $\longrightarrow$ son versos en un poema sin título de Danza de la muerte (Panero, 2011a: 231); «La nariz de Góngora y los labios de Orfeo» se lee en «Roca» de Versos esquizofrénicos (2007), versos a los que antecede un intertexto de César Vallejo y les sucede otro de Rainer Maria Rilke (Panero, 2011a: 349), caso de citas encadenadas; «¿Quién sino un perro a la nada atado? / "Gime el lebrel en el cordón de seda" / Góngora lo dijo, a una cuerda atado / Para blasfemar contra la vida y el alma» en el poema XLI de Mi lengua mata de 2008 (Panero, 2011a: 431), donde de nuevo la cita no es exacta y además es ocasión en la que se interpreta lo que habría querido decir Góngora y que no es sino una inserción de su verso en el mundo paneresco.

Por otra parte, en Los héroes inútiles, el curioso epistolario entre Panero y Diego Medrano de 2005 , se lee en una «prosa poética» que, pese a esa indicación, es en verso, que constituye una de las cartas del poeta: «pisando la dudosa luz del día / como dijera Góngora, con un puñal escondido bajo el ala, / pisando la dudosa luz del día» (Panero y Medrano, 2005: 29-30). En ese mismo libro, de textos bastante disparatados, da cuenta Panero en una de sus cartas de que

Ayer comí pollo frito y leí cosas mías sobre el barroco español: Góngora, Quevedo, Juan de Jáuregui, los Argensola [...] Las enfermeras gordas se llevan mis Argensola, y los enfermeros pegahostias mi tomito de Góngora, editado en piel por Aguilar. (Panero y Medrano, 2005: 169)

\footnotetext{
${ }^{6}$ En mis ediciones de la poesía de Leopoldo María Panero (Panero, 2001, y 2011a), corregí las erratas evidentes y no poco numerosas de las primeas publicaciones, tal como señalé en las correspondientes introducciones; otros casos, como el que suscita esta nota, que responden con toda probabilidad, por no decir con total seguridad, a ser citas hechas de memoria, tal como digo en el texto,, los consulté por teléfono o por carta con el poeta y, como es natural, seguí sus decisiones, por mucho que le hubiera insistido en lo erróneo de la cita y le enviara fotocopias que lo mostraban. Ya me referí a esto en (Blesa, 2014, n. 17), donde comento un caso de atribución trastrocada.
} 
Lo de «leí cosas mías sobre el barroco español», salvo que se refiera a algún o algunos escritos no publicados, habrá que entender que se refiere a los pasajes en que se trata de ello en el texto de 1979 «Última poesía no española», reeditado en Prosas encontradas en 2004 y que Panero pudo releer durante la redacción de las cartas de Los héroes inútiles, que se publicarían en 2005. Por lo demás, si se da crédito a lo que ahí se lee — no desde luego a lo de «enfermeros pegahostias», que forma parte de las no escasas exageraciones o falsedades del trato recibido en algunos de sus internamientosPanero habría tenido a mano diversos volúmenes de poetas barrocos.

Como ha quedado dicho, la primera inserción gongorina en la poesía de Panero es en Contra España y otros poemas no de amor. En ese mismo libro se lee en tres ocasiones Filis, el nombre poético de la amada tan repetido en la escritura barroca, entre otros, en Lope de Vega, en Quevedo, en Lupercio Alejandro de Argensola, en Calderón y, claro está, en varios de los textos de Góngora. Así, puede afirmarse que las apariciones de Filis en «cómo Filis me abraza y la ciudad se rinde», «Filis, al fin lo digo, la flor / que en el poema se buscaba / significaba la tumba» y «La flor, Filis, al fin lo digo / significaba la ausencia» (Panero, 2001: 385, 396 y 400) han de provenir de la lectura de la poesía del cordobés, presumiblemente próxima a la redacción de los poemas, lo que se sustenta además en el hecho de que no hay huella en el libro de Panero de ningún otro de los escritores barrocos. Por otra parte, está la presencia de «lebrel», indiscutible en los ejemplos antes citados, y «concento» en varios poemas de diferentes libros, si bien, aunque es probable su filiación gongorina, no deja de ser discutible.

Finalmente de los varios libros de poesía de los últimos años hay que añadir tan solo un par de casos: «Dos brasas son los ojos del suicida / Dos armas para saciar la noche / Góngora atroz contra la espada / oh verso a lo negro, canto a la espada», en el poema IX de Cantos del frío (Panero, 2011b: 15); parte del estribillo de la letrilla «Ándeme yo caliente» se inserta en «la espada sea mi diente, y ríase la gente, / Góngora lo dijo», poema de El ciervo aplaudido (Panero, 2012: 23). Finalmente, en uno de los libros de prosas de Panero, el ya mencionado Papá, dame la mano que tengo frío se lee: «Oh soledad de Góngora sobre el papel, soledad del muslo en llamas, artífice viejo del silencio, mecanismo secreto de la amargura» (Panero, 2007: 79).

Estas huellas gongorinas no son las únicas de escritores barrocos y, más extensamente, del período áureo, lo que quiere decir, claro está, que hay algunas otras. Es el caso de «animal hispano, bestia que no perdonas / el genio y no tuviste nunca caridad / mientras San Juan de la Cruz llora en la pradera de la noche» de un poema de Guarida del animal que no existe de 1998 (Panero, 2001: 531), donde parece que ha de leerse una equiparación entre la persecución que sufrió Juan de Yepes y la que habría padecido Panero, de lo que hay varias otras manifestaciones en sus textos; «Estando ya mi casa sosegada» de «Noche oscura» es epígrafe en un poema del libro inmediatamente siguiente al que se acaba de citar, Teoría lautreamontiana del plagio, de 1999 (Panero, 2001: 562); «Quién nos dirá las compañas / de la que va por ínsulas extrañas» figura como epígrafe en un poema de Los señores del alma de 2002 (Panero, 2011a: 154), donde se reescribe con modificación «mas mira las compañas / de la que va por ínsulas extrañas» del «Cántico espiritual»; también es cita previa «le di a la caza alcance» 
en «Poema esteticista» de ese mismo libro (Panero, 2011a: 165); años después el final del «Cántico» se incorpora en «Hay clavos en la rosa / "y la caballería, a vista de las aguas descendía", San Juan lo dijo / Han traído cenizas al banquete de Eleusis», que son los primeros versos del poema XXVIII del libro de 2010 Reflexión (Panero, 2011a: 562), caso de «X dixit» e intertexto que, como sucede en alguna otra ocasión en esta poesía de la reescritura, enlaza con otro, ahora con modificación, que está tomado de Ezra Pound, «They have brought whores for Eleusis», The Cantos, XLV, verso incorporado en diversas ocasiones en la escritura paneresca; finalmente, «Y quédeme no sabiendo / toda ciencia trascendiendo» es el colofón, de oportuno ha de calificarse en una poesía como la de Panero, de Poemas del pájaro y la oruga (Panero, 2014a: 39).

Por lo demás, se incluye uno de los versos más conocidos de Canción a las ruinas de Itálica de Rodrigo Caro en uno de los poemas de Buena nueva del desastre (2002): «mientras llovía sobre la nada / y lágrimas caían imitando al césped / —campo de soledad, mustio collado (Rodrigo Caro)—》 (Panero, 2011a: 118). También cuenta con una única aparición la obra de Lope de Vega; se trata de cinco versos de El caballero de Olmedo de Lope de Vega, «Sombras le avisaron / que no saliese, / y le aconsejaron / que no se fuese / el caballero», lema de la serie de poemas de 2010 titulada Poesía (Panero, 2011a: 574).

Mayor atención reclaman las ocurrencias en la obra de Panero del nombre y algunos versos de Gabriel de Boncángel y Unzueta y las menciones de este poeta. En los poemas escritos a partir de los arcanos mayores del tarot, El Tarot del inconsciente anónimo de 1997, el que surge de la carta XIIII, «La templanza», comienza con estos versos: «Bebe, Bocángel lo dijo / la sed en vaso que no bebe» (Panero, 2001: 517), que se corresponde, levemente modificado, con «bebe la sed en proceloso vaso / y bebe sed de vaso que no bebe», que se lee en la Fábula de Leandro y Hero. ${ }^{5}$ El verso tiene alguna otra ocurrencia en la escritura de Panero y, aparte de otras razones, cabe tener en cuenta su conocida dipsomanía, de la que hay no pocas noticias en la biografía de J. Benito Fernández El contorno del abismo (Fernández, 1999) y varios testimonios en los propios escritos del poeta, de los que citaré tan solo estas palabras de Prueba de vida, donde la dependencia del alcohol se expresa como relación amorosa y se da cuenta del final al que conduce: «Desde hace tiempo tengo una mujer, llamada orujo, llamada cazalla. Los alcohólicos necesitamos compañía, pero la bebida nos deja solos» (Panero, 2002: 15). El verso regresa retocado en «bebes la sed en vaso que no bebe (Bocángel dixit)» en uno de los poemas añadidos en la segunda edición de Teoría del miedo (Panero, 2011a: 80) y también en «Bebe la sed en vaso que no bebe», epígrafe en uno de los poemas de Conjuros contra la vida, 2008, cuyo primer verso lee en un juego el apellido del poeta: «Ah, boca del ángel» (2011a: 492), semejante a las varias ocasiones en que Mallarmé se reescribe como «Ma larme» o «ma larme», así en uno de los poemas de Danza de la muerte: «con el dolor de la boca / que gime aún sobre el papel / Mallarmé, $M a$ larme / mi lágrima que no es nada» (2011a: 220).

En «Teoría del plagio» del libro de 2008 Sombra, se vuelve a reescribir ese mismo verso, pero ahora encadenado a otra cita, con leve modificación, del mismo poeta: «España contra España, ejército del viento / Fe única del silencio, república del viento / Bocángel lo dijo / Bebe la sed en vaso que no 
bebe / También Bocángel lo dijo» (Panero, 2011a: 361). En efecto, el soneto «Huye del sol el sol, y se deshace» dice al final: «república de viento / que tiene por monarca un accidente»; cita que se repite en otro poema de ese mismo libro: «Pecado imperdonable del silencio / "República del viento / Que tiene por monarca un accidente" / Bocángel lo dijo, humillando al viento» (Panero, 2011a: 366) y también en otro de Mi lengua mata, publicado en el mismo año que el citado: «Oh tú, vida hedionda / "República de viento / Que tiene por monarca un accidente" / Bocángel lo dijo para alimentar la tristura» (Panero, 2011a: 426). Todos estos intertextos, alguno incluso con la figura «X dixit», dan pie a sostener que cuando, años antes, en el poema «Alba» se lee «Beber sólo sed en el vaso / que contiene el mar» (Panero, 2001: 168) se trata de una cita rehecha del verso de la Fábula de Leandro y Hero, además de que ese poema pertenece a Narciso en el acorde último de las flautas, publicado en 1979, el mismo año en que la revista Poesía dio a conocer «Última poesía no española», donde, como ya ha quedado recogido más arriba, no faltan las menciones de Bocángel.

He dicho que estas citas de Bocángel reclamaban una mayor atención y ello no sólo por las citas en sí mismas, que también, de hecho las de ese poeta son cuantitativamente las segundas de entre los poetas barrocos tras las de Góngora en los escritos de Leopoldo María Panero; no sólo, pues, sino por lo que se dice de él en algunas otras menciones.

«Última poesía no española» es sin duda una antología singular y una de las razones de esa singularidad es que en la selección de textos figuran poemas de la poesía española reciente tal como se espera del título, pero también un soneto de Bocángel, el titulado «A un soldado de quien se refiere que, matándole en un hecho de armas, se quedó en pie después de muerto», cuyo tema, la muerte viva o la vida muerta, según se prefiera, no es en absoluto ajeno a la obra paneresca. En Narciso, publicado en ese mismo año, la sección VII incluye este epígrafe «(Mi madre me contó de niño que, allá por el tiempo de esa remota leyenda que llaman "guerra de España", a alguien le seccionó un obús la cabeza y siguió andando.)» (Panero, 2001: 180) Además de la noticia de la propia muerte o «esa triste ficción del "yo" [...] al fin murió» en la solapa de Teoría de 1973 (Panero, 2001: 77-78), en el prólogo de Narciso, el personaje del que habla, un «escritor imaginario», desdoblamiento del poeta, «al fin murió», «la muerte vino de nuevo a desterrarlo», una muerte que habría sido una «muerte figurada» (Panero, 2001: 141, 142 y 143); en ese mismo libro la sección primera se titula «Luz de tumba» y su poema inicial «Pavane pour un enfant défunt» (Panero, 2001: 144), por mencionar unos pocos casos, vuelven sobre la cuestión.

Pese a ello, extraña inclusión en ese conjunto de última poesía, como extraño es el argumento con el que Panero la justifica: «Incluyo un poema de Gabriel Bocángel, que pertenece a mi generación» (Panero, 2014b: 493). Extraño al tiempo que iluminador de cómo en el pensamiento literario de Panero la poesía barroca, la que habría roto con el referente para proyectarse en el lenguaje mismo, la que, como ningún otro, ejemplifica la obra de Góngora, quien, como escribe Panero «jamás escribió en este idioma [el español]» (Panero, 2014b: 491), quien, en palabras de Hervás que se hacen propias, ya citadas antes, «lo que hizo fue quizá tratar de inventar una nueva lengua», lo que se repite en otro escrito de 1989: «Góngora, cuyo lenguaje rebasó los límites de cualquier idioma y se separó de su 
referente» (Panero, 2014b: 258), lo que en definitiva se correspondería, como ha quedado dicho, con la «Literatura misma»o «literatura orgánica»y, en fin, con el proyecto novísimo.

Otro testimonio de la estima que la poesía de Bocángel le merecía a Panero es que, en «Última poesía no española», para ponderar el valor de la poesía de Gimferrer escribirá: «Pedro Gimferrer creador de lo que los horteras llaman "escuela veneciana"- es el autor de Arde el mar, libro genial, casi como Bocángel» (Panero, 2014b: 492). Gimferrer, a quien, según se lee en el artículo «La poesía de Pere Gimferrer», se debería una poesía en la que «el referente de la poesía, como ocurre en Mallarmé, es la poesía misma» (Panero, 2014b: 258). También allí, tras la declaración de quiénes serían los dos gigantes de la poesía española actual y «equiparar a Gimferrer con Góngora», como se recordará, Leopoldo María Panero escribe:

Por lo que se refiere a mi persona, podría equipararme, no siendo Quevedo de mi predilección, con su contemporáneo don Gabriel de Bocángel y Unzueta, que escribió versos tan magníficos como "y bebe la sed de vaso que no bebe" y que fue discípulo de la Belleza. Creo que Gimferrer y yo somos la única poesía válida de este país (Panero, 2014b: 259).

A estos textos de 1979 y 1989 hay que agregar otro de Los héroes inútiles, de 2005, y, como he apuntado, escrito teniendo probablemente a la vista la recopilación de aquellos en la recopilación de 2004 Prosas encontradas. En una de las cartas escribe Panero: «El único friend que yo he tenido ha sido Gimferrer. Él era para mí Góngora, yo para él Gabriel de Bocángel y Unzueta, quien escribió: bebe la sed en vaso que no bebe». (Panero y Medrano, 2005: 178)

Como ya ha quedado aquí citado del artículo de 1989, Panero veía a la pareja formada por Gimferrer y él mismo, y por dos ocasiones distantes en el tiempo, como «los dos gigantes de la poesía española actual» y para calibrar esa elevada talla el poeta no encuentra otro punto de comparación que los gigantes Góngora y Quevedo, sustituido este por cuestión de aprecio personal por Bocángel y, por lo que dice, no sólo sería en su opinión, sino que también para Gimferrer Panero era Bocángel, todo lo cual hace a Panero, utilizando sus mismas palabras, «discípulo de la Belleza».

Salvo error u omisión, no podría faltar la socorrida fórmula, las citadas son las ocasiones en que en los escritos de Leopoldo María Panero se leen fragmentos incorporados de Góngora y otros poetas barrocos y algunas otras menciones de estos. Si bien no se puede decir que sean numerosas en comparación con la de textos apropiados de obras de las literaturas en inglés, francés e italiano y algún otro en otra lengua, además de otros de la literatura hispánica, sí son significativas por cuanto evidencian el interés por lo barroco entre los poetas novísimos, y utilizo la expresión siempre en sentido no restringido a los seleccionados en Nueve novísimos, en lo que fue una nueva hora de Góngora (Blesa, 2017). En el caso de Panero, como hemos visto, los predilectos son Góngora y Bocángel y si los intertextos de estos poetas, como los de los otros poetas barrocos, responden al culturalismo general que caracteriza a tales poetas, sirven también a Panero para ejemplificar antecedentes de una poética sin referente o, como el propio poeta denomina, la poética de la «Literatura misma» o «literatura orgánica», una poética que sería la del propio Panero y, de modo general, la de los novísimos. 


\section{Bibliografía}

BLESA, Túa (1990): Scriptor ludens. Ensayo sobre la poesía de Ignacio Prat, Zaragoza, Lola Editorial. (2001): «La destruction fut ma Beatrice», en Panero (2001), 7-20.

(2008): «Escritura sin escritura: doble escritura», Revista Jinzo de Himanidades, III, 6-7, 3945.

(2014): «Leopoldo María Panero, la literatura orgánica y el estructuralismo», L’Âge d'Or, 7, 2014, s. p., http://lisaa.u-pem.fr/revues-en-ligne/lage-dor/texte-integral-du-n7-2014/ (última consulta, 1-9-2017).

_ (2017): «“(¡Gong!) [...] (¡hora)!” escribió Ignacio Prat: la huella de Góngora y otros barrocos en la poesía de los novísimos», La razón es Aurora. Estudios en homenaje a la profesora Aurora Egido, Ángeles Ezama et alii, eds., Zaragoza, Institución Fernando el Católico, 213-222.

(en prensa): «Leopoldo María Panero ante la literatura», Actas del Congreso «Leopoldo María Panero: La palabra poética y sus límites», Javier Huerta Calvo, ed.

CAMPBell, Federico (1971): «Leopoldo María Panero o el mundo del silencio», Infame turba, Barcelona, Lumen, 17-25.

FERNÁNDEZ, J. Benito (1999): El contorno del abismo. Vida y leyenda de Leopoldo María Panero, Antonio Martínez Sarrión, pról., Barcelona, Tusquets.

MARTínez FERnÁndeZ, José Enrique (2001): La intertextualidad literaria (Base teórica y práctica textual), Madrid, Cátedra.

MESQUIDA, Biel (1977): «Leopoldo María Panero nombra y recita los protagonistas de la revolución», El Viejo Topo, 5, febrero, 11-14.

OulIPO (2010): C'est un métier d'homme. Autoportraits d'hommes et de femmes en repos, París, Mille et une nuits.

PANERO, Leopoldo María (1977): «Prólogo», en Visión de la literatura de terror anglo-americana, LMP, ed. y pról., Madrid, Felmar.

— (2001): Poesía 1970-2000, Túa Blesa, ed. y pról., Madrid, Visor.

- (2002): Prueba de vida. Autobiografía de la muerte, Madrid, Huerga y Fierro.

(2007): Papá, dame la mano que tengo miedo, Ana María Moix, pról., Barcelona, Cahoba Ediciones.

(2011a): Poesía 2000-2010, Túa Blesa, ed. y pról., Madrid, Visor.

(2011b): Cantos del frío, Madrid, Casus-Belli.

- (2012): El ciervo aplaudido, Ianus Pravo, pról., Michela Scala, intr. y fotografías, Las Palmas de Gran Canaria, el ángel caído.

- (2014a): Poemas del pájaro y la oruga, Madrid, Ediciones Vitruvio.

— (2014b): Prosas encontradas, Fernando Antón, ed. y pról., Madrid, Visor.

— y Diego Medrano (2005): Los héroes inútiles, Luis Antonio de Villena, pról., Castellón, Eliago Ediciones.

PrAT, Ignacio (1983): Para ti. 1963-1981, José Luis Jover, ed., Valencia, Pre-textos. 
Tropelías. Revista de Teoría de la Literatura y Literatura Comparada, número extraordinario 1 (2017) 63 «Góngora [...] inventar una nueva lengua» escribió Leopoldo María Panero: la huella...

RODRÍGUEZ DE ARCE, Ignacio (2009): «Poética de la intertextualidad en Leopoldo María Panero», Ogigia. Revista electrónica de estudios hispánicos, 6, http://www.ogigia.es/OGIGIA6.html, 2737 (última consulta, 1-9-2017).

SÁncheZ RobAyna, Andrés (1983): «Un debate inconcluso. Notas sobre Góngora y Mallarmé», Revista de la Universidad de México, 30, octubre, 17-24. 